\title{
The Significance of Measuring Vitamin D Serum Levels in Women with Uterine Fibroids
}

\author{
Michał Ciebiera ${ }^{1,2}$ (D) $\cdot$ Mohamed Ali $^{2,3} \cdot$ Lillian Prince $^{4} \cdot$ Stanisław Zgliczyński ${ }^{5} \cdot$ Grzegorz Jakiel $^{6} \cdot$ Ayman Al-Hendy $^{7}$
}

Received: 1 June 2020 / Accepted: 19 October 2020 / Published online: 27 October 2020

(C) The Author(s) 2020

\begin{abstract}
Uterine fibroids (UFs) are benign tumors originating from smooth muscle cells and are considered a common pathology that affects numerous women which is a notable socio-economic problem. Several UF risk factors have been identified including black race, obesity, and vitamin D deficiency. Vitamin D is steroid compound with pleiotropic effects on the human body. Vitamin D deficiency is a major public health concern worldwide. Several studies have shown that the majority of UF patients experienced hypovitaminosis D. In addition, sufficient vitamin D serum levels are associated with the reduced risk of UFs. In this review, we present available data highlighting the importance of measuring vitamin D serum levels in women with UFs and women at a high risk for UF development. We proposed a preliminary clinical instruction of 25 -hydroxyvitamin D measurements and vitamin D supplementation for clinicians who are involved in the treatment of patients with UFs. Achieving sufficient serum levels of vitamin D might be of interest in patients with UFs. Screening, supplementation, treatment guidelines, and public health strategies for vitamin D deficiency in women with UFs as well as women at a high risk of UF development might be of potential importance as well.
\end{abstract}

Keywords Uterine fibroid $\cdot$ Leiomyoma $\cdot$ Vitamin D $\cdot 25$-hydroxyvitamin D $\cdot$ Serum level $\cdot$ Risk factor

Michał Ciebiera

michal.ciebiera@gmail.com

1 Second Department of Obstetrics and Gynecology, Center of Postgraduate Medical Education, ul. Cegłowska 80, 01-809 Warsaw, Poland

2 Department of Surgery, University of Illinois at Chicago, Chicago, IL, USA

3 Clinical Pharmacy Department, Faculty of Pharmacy, Ain Shams University, Cairo, Egypt

4 Biological Sciences Division: Public Health Sciences, University of Chicago, Chicago, IL, USA

5 Department of Internal Diseases and Endocrinology, Central Teaching Clinical Hospital, Medical University of Warsaw, Warsaw, Poland

6 First Department of Obstetrics and Gynecology, Center of Postgraduate Medical Education, Warsaw, Poland

7 Department of Obstetrics and Gynecology, University of Chicago, Chicago, IL, USA

\section{Introduction}

\section{Uterine Fibroids-Disease Significance}

Uterine fibroids (UFs), also known as leiomyomas, are benign tumors originating from smooth muscle cells. They are considered a common pathology that affects many women which is a notable socio-economic problem [1,2]. Various studies showed that by the age of 50, the prevalence of UFs is around $70 \%$ and extends to $80 \%$ in African American (AA) population $[1,3]$. Several UF risk factors were identified including, most importantly, black race, older age, vitamin D deficiency, obesity, family history, low parity, long period since last labor, food additives or soybean milk consumption, and hypertension $[4,5]$.

Although commonly benign, UFs are associated with significant morbidity. Although some UF patients may be asymptomatic, $25-50 \%$ of them may present a wide range of severe and chronic symptoms, such as abnormal uterine bleeding (AUB), anemia, pelvic pain and pressure, gastrointestinal problems, subfertility, and various obstetric complications [1, $6,7]$. Thus, symptomatic UFs generate an enormous 
healthcare burden worldwide $[1,8,9]$. Nowadays, the main therapeutic modalities in UF treatment include expensive surgical procedures (hysterectomies or myomectomies). Therefore, there is an urgent need for alternative and preventive therapeutics especially for women who still pursue future fertility plans [8]. According to Merrill et al., UFs are responsible for $30 \%$ of all hysterectomies in women of reproductive age [10]. Moreover, US hospital admissions have increased by more than a fifth for 10 years [11].

\section{Vitamin D Metabolism}

Vitamin D is a steroid compound with pleiotropic effects on the human body. Vitamin D receptors (VDRs) are found in various organs including those in the female reproductive tract $[12,13]$. Vitamin D exists in two different isoforms: ergocalciferol (vitamin $\mathrm{D}_{2}$ ), which is found in plants or yeast, and cholecalciferol (vitamin $\mathrm{D}_{3}$ ), which is introduced to the body with nutrition or synthesized via ultraviolet radiation $[14,15]$. The major sources of vitamin D are fatty fish, cod liver oil, or egg yolks [16]. In some countries, it is also added to fortified milk as well as to some yogurts, juices, and breakfast cereals [17].

Vitamin D deficiency is a major public health concern worldwide $[17,18]$. Generally, vitamin D deficiency results from (1) low vitamin D consumption in the diet and low sun exposure, (2) the inability to absorb intestinal vitamin D, (3) the lack of biological vitamin $\mathrm{D}$ activation in the kidneys, the liver, or both $[19,20]$. Several consequences are associated with vitamin D deficiency including infections, autoimmune diseases, cardiovascular diseases, different types of diabetes, neurocognitive or psychiatric diseases, cancer, or adverse pregnancy outcomes [21-23]. Additionally, recent metaanalyses showed that low serum vitamin D level increased the risk of all-cause mortality [24], while vitamin D supplementation might reduce the risk of death in oncological patients [25].

The metabolism of vitamin D starts in the skin under the influence of sunlight (Fig. 1).
The amount of needed sunlight may vary depending on the exposure time, age, race, clothing, and accompanying medical problems [26]. Nutrition intake traditionally plays a relatively minor role. However, in some areas, due to the lack of sunlight, vitamin D supplementation may be important [17]. Endogenous vitamin D production is limited by factors like geographic latitude, season, weather conditions, clothing, and the use of sunscreens [27]. The biological production of vitamin $\mathrm{D}$ changes during the lifespan with the production decreasing with age $[14,22,26]$. People with darker skin pigmentation (e.g., AA or Latinos) need more sun exposure to produce adequate amounts of vitamin D [19].

\section{Serum Vitamin D Level Clinical Definitions}

There is an ongoing debate among experts regarding the identification and terminology of vitamin D deficiency [28-31]. The most accurate way to measure vitamin $\mathrm{D}$ serum levels in the human is the 25-hydroxyvitamin D [25(OH)D] blood test [32,33]. According to the Endocrine Society 2011 guidelines, vitamin D deficiency is defined as $25(\mathrm{OH}) \mathrm{D}$ levels of $20 \mathrm{ng} /$ $\mathrm{mL}$ or lower, insufficiency as $21-29 \mathrm{ng} / \mathrm{mL}$, and sufficiency as $30 \mathrm{ng} / \mathrm{mL}$ or higher $[31,34]$. Phudowski et al. described the optimal concentration of $25(\mathrm{OH}) \mathrm{D}$ to be ranging from 40 to $60 \mathrm{ng} / \mathrm{mL}$ to achieve its best pleiotropic effect while maintaining a low risk of toxicity [28]. The scientific debate among scientific committees responsible for clinical instructions is over the serum level at which vitamin D supplementation is recommended [33]. For example, according to the US Institute of Medicine (IOM), no additional benefit was associated with achieving $30 \mathrm{ng} / \mathrm{mL}$ serum $25(\mathrm{OH}) \mathrm{D}$ concentrations compared to $20 \mathrm{ng} / \mathrm{mL}$, and this level should be treated as sufficient [30].

\section{Uterine Fibroids Biology_Overview}

UFs are composed of abnormal smooth muscle cells placed in an extensive amount of altered extracellular matrix (ECM) [35-37]. UF growth is hormone-dependent, so UFs are rarely observed in girls before menarche; they become more

Fig. 1 Vitamin D metabolism. UV, ultraviolet; 25(OH)D, 25hydroxyvitamin $\mathrm{D} ; 1,25(\mathrm{OH}) \mathrm{D}$, 1,25-dihydroxyvitamin D

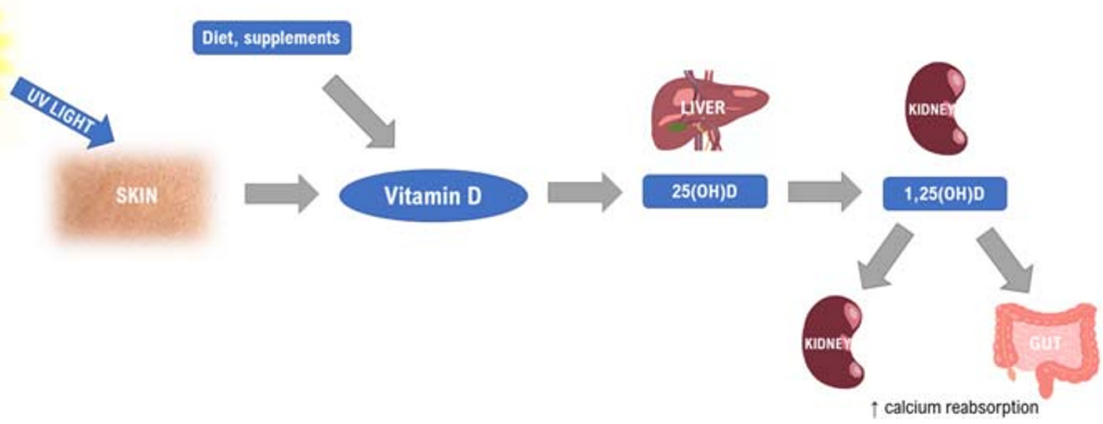


prevalent among women aged 35-45 and are mostly repressed in postmenopausal women $[6,35]$. Estrogen and its receptors were traditionally thought to play a major role in UF growth. Interestingly, new studies showed that progesterone played a significant role in UF growth and estrogen mainly induced progesterone receptor expression [38, 39]. These steroid hormones induce growth factors and cytokines which affect tumor biology and growth as well as the accumulation of ECM [37, 40, 41]. Numerous UF-derived symptoms may be explained by cytokine influence [41, 42]. Transforming growth factor $\beta$ (TGF- $\beta$ ) appears to be one of the most involved growth factors in UFs considering its role in fibrosis [41, 43]. Additionally, the inflammatory process highly contributes to tumor biology via several cytokines [41, 44].

\section{The Role of Vitamin D in Uterine Fibroid Biology-Overview}

In 2009, active vitamin D was found to effectively inhibit cell growth in vitro [12]. Since then, accumulating data have emerged showing that vitamin D deficiency might be strongly associated with the development and growth of UFs [13, 45]. In 2016, Al-Hendy et al. found a strong connection between vitamin D deficiency and known pathways involved in UF pathology [46]. They showed that UFs with MED12 gene somatic mutations exhibited the upregulation of the $\mathrm{Wnt} / \beta$ catenin pathway in comparison with the adjacent myometrium. Moreover, vitamin D treatment inhibited such activation of $\mathrm{Wnt} / \beta$-catenin and downregulated the expression of mammalian target of rapamycin (mTOR) signaling in both cell types. Those interesting findings suggested that vitamin D might have the potential to inhibit major pathways in UF biology, including those connected with TGF- $\beta$ [46]. Additionally, vitamin D was reported to have immunologic properties via the vitamin D receptor (VDR) in reproductive tissues $[13,45]$ as well as anti-inflammatory functions [44, 47]. Recently, the same group has found that vitamin D deficiency might be associated with an increased expression of steroid receptors in murine myometrium in addition to an increased expression of genes related to proliferation, fibrosis, exaggerated inflammation, and DNA damage in murine myometrium [47].

The role of progesterone was mentioned before. Moreover, some findings concerned a potential connection between progesterone and vitamin D pathways that suggested that both steroid hormones cooperated with each other for a more effective regulation of the immune system. For example, it is believed that progesterone induces VDRs in T cells for enhanced regulation by vitamin $\mathrm{D}$ and vitamin $\mathrm{D}$ is an important regulator of $\mathrm{T}$ cell-dependent inflammatory responses [48]. However, data are still scarce in this matter in UF research.

Several studies showed that the majority of UF patients experienced hypovitaminosis D [49-51]. In addition, some authors believe that sufficient vitamin D serum levels might be associated with a reduced risk of UFs [49]. Studies showed vitamin D as a potential single [52] or combination treatment $[53,54]$. These topics will be described later on in this manuscript.

A review of the literature indicated that not many studies investigated vitamin D serum levels in patients with UFs. Therefore, it is necessary to conduct additional research to develop recommendations concerning vitamin D screening in women with UFs or at a high risk of developing UFs, similar to recommendations for testing pregnant women who are at an increased risk of vitamin D deficiency (e.g., women with limited sun exposure, women with darker skin). Clearly, several clinicians might be unaware that vitamin D deficiency may contribute to UF development.

\section{Aim of the Review}

In this review, we present the available data highlighting the importance of measuring vitamin D serum levels in women with UFs and women who are at a high risk of their development. We also provide preliminary clinical guidance proposal in this aspect.

\section{Materials and Methods}

This article presents a narrative review on the significance of vitamin D measurements in women with UFs or in women who are at a high risk of UF occurrence. The authors conducted an extensive search in PubMed of the National Library of Medicine and Google Scholar. A literature search was mainly performed using the following keywords: "uterine fibroid" and "vitamin D." All relevant studies related to UFs and vitamin D published in English until August 2020 were included in this review. We focused on the correlation between vitamin D deficiency and UFs as well as UF-related clinical symptoms. The authors also proposed a preliminary clinical guidance for clinicians who might be involved in the treatment process of patients with UFs or at a high risk of developing UFs.

\section{Discussion}

\section{Vitamin D Deficiency_Epidemiology and Current Measurement Indications}

Low serum vitamin D is a tangible worldwide problem, especially in women from the Middle East as described by Palacios and Gonzalez. Moreover, data are scarce in several countries, mostly in Africa and South America [55]. 
Surprisingly, the levels of $25(\mathrm{OH}) \mathrm{D}$ reported in several studies revealed that the majority of the populations are vitamin $\mathrm{D}$ deficient, especially during winter and spring $[14,55,56]$.

Low 25(OH)D serum level is a marker of poor health [57], as vitamin D status might be associated with various diseases [24]. Vitamin D deficiency is also a consistent finding across age, ethnicity, and latitude in obese people [58]. These findings might sound intimidating. Many reports and data without any systematic analysis lured many physicians to routinely test $25(\mathrm{OH}) \mathrm{D}$ levels in their healthy patients. In fact, current medicine did not show a practical reason for most people to be tested for vitamin D deficiency. According to recommendations published in 2015 by the United States Preventive Services Task Force (USPSTF), whole population screening for vitamin D deficiency is not recommended for healthy, non-pregnant adults or elderly who are seen at family care settings and do not present any signs or symptoms of vitamin $\mathrm{D}$ deficiency or conditions for which vitamin $\mathrm{D}$ supplementation is recommended [59]. Conversely, 25(OH)D serum level measurements might be important in people who are at risk of deficiency or have medical conditions that increase that risk $[19,33]$.

There are ongoing scientific discussions and consensus dilemma to determine normal cut-offs for serum vitamin $\mathrm{D}$, as well as the legitimacy of such tests. For example, in France, the indications for serum vitamin D level measurement were restricted only to rickets, osteomalacia, elderly with a high risk of fractures, kidney transplant recipients, and adults after bariatric surgery. According to Souberbielle et al. (2016), such indications were too strict. A group of French clinicians proposed a different approach where bone fragility, chronic renal failure, malabsorption, and other clinical signs suggesting vitamin D deficiency or vitamin D toxicity should also be taken into consideration for vitamin D measurements [60]. Notably, diseases that affect the intestinal absorption of vitamin $\mathrm{D}$ should be considered, such as extensive surgical resections, celiac disease, or Crohn's disease [61].

Recently, in 2017, Sowah et al. found that shift, indoor, and healthcare workers were among the high-risk groups of vitamin D deficiency. It could be corroborated by missing plenty of sunlight exposure during lifetime due to their duties. Some groups of medical students (72\%) and resident doctors $(65 \%)$ were particularly at risk for the same reason [62].

The increased public awareness of vitamin D deficiency and subsequent complications resulted in higher vitamin D consumption. Nevertheless, it should be used following physician consultation, since vitamin $\mathrm{D}$ is still a hormone that might exert a potent influence on various tissues.

\section{Vitamin D and Uterine Fibroids-Current View}

Recent preclinical in vitro and animal studies showed that vitamin $\mathrm{D}$ is a potent anti-UF agent [13, 63-66]. According to Halder et al. (2011), 1,25-dihydroxyvitamin D reduced ECM-associated protein expression in immortalized human UF cells [67]. Another study by Sharan et al. showed that vitamin D inhibited the growth and proliferation of UF cells through the downregulation of proliferating cell nuclear antigen (PCNA), cyclin-dependent kinase 1 (CDK1), and B cell lymphoma $2(\mathrm{Bcl} 2)$ and suppressed the expression and activity of catechol-O-methyltransferase (COMT) [68]. In 2012, Halder et al. found that vitamin D treatment significantly decreased the size of UFs in the Eker rat animal model through the suppression of cell proliferation [69]. In 2018, Othman et al. reported that UFs contained significantly lower levels of active vitamin $\mathrm{D}$ than the adjacent myometrium. The authors suggested that the overexpression of 24-hydroxylaze enzyme might be a mechanism by which those tumors were under the state of hypovitaminosis D [70]. As mentioned earlier, vitamin $\mathrm{D}$ reduced $\mathrm{Wnt} / \beta$-catenin activation and led to the downregulation of mTOR signaling expression [46]. Moreover, in 2018, Elhusseini et al. found that low serum levels of vitamin D in mice were associated with an increased expression of sex steroid receptors in the myometrium and an increased expression of proliferation, fibrosis, and inflammation-related genes. In this study, the authors also presented that vitamin D deficient diet-enhanced DNA damage in the myometrium which may increase the risk of fibroid development later in life [47]. Vitamin D is involved not only in cell cycle regulation and cell differentiation, but it plays an important role in inflammatory and DNA repair processes [42]. More recently, in 2019, Ali et al. found that 75 DNA repair genes were downregulated after VDR knockdown while the expression of 67 of those genes was restored after treatment with vitamin D. Those findings suggested a novel link between DNA damage and the pleiotropic role of vitamin D. The authors concluded that vitamin D suppressed UF phenotype through orchestrated targeting at different networks in DNA repair [71]. A recent animal study by Corachan et al. in 2020 revealed that short-term treatment with vitamin D did not change UF size. However, long-term use of higher doses induced a significant lesion volume reduction via reduced cell proliferation, reduced TGF- $\beta 3$ expression, and increased apoptosis [72].

Recently, clinical trials exploring vitamin D effect in women with UFs have started. In 2016, Ciavattini et al. showed that vitamin D could reduce disease progression in small lesions [52]. In 2019, Corachan et al. used samples collected from women undergoing surgery and found that an increased proliferation and abnormal functioning of the $\mathrm{Wnt} / \beta$-catenin pathway played a crucial role in the biology of UFs, whereas apoptosis appeared not to be contributory. Vitamin D showed an anti-proliferative effect through cell growth arrest and the $\mathrm{Wnt} / \beta$-catenin pathway inhibition. The study suggested that vitamin $\mathrm{D}$ itself might play a smaller role in reducing tumor size and it mostly stabilized its volume and prevented further 
growth [66]. It might suggest combining vitamin D with other agents that induce excessive apoptosis. Ulipristal acetate (UPA) has a proven role as a compound that might reduce UF volume and clinical symptoms. It is a multifactorial agent that works through reducing cell proliferation rate, inducing apoptosis, and regulating ECM remodeling [73]. Interestingly, in 2019, Ali et al. showed that vitamin D combined with UPA significantly reduced cell proliferation compared to UPA alone. Such co-treatment significantly decreased the protein expression of proliferation markers in comparison with UPA therapy alone, along with a significant increase in apoptosis induction. Such a combination also decreased ECM-derived protein levels and diminished the production of proinflammatory interleukins in UFs in comparison with UPA alone (e.g., interleukins $1 \alpha, 1 \beta, 6,8)$ [53]. The simultaneous use of UPA and vitamin D in humans was described in two cases. The combination presented good clinical effectiveness as the agents shared synergistic anti-fibroid properties [54]. However, recent reports of potential liver toxicity by UPA raised concerns regarding its use $[74,75]$.

To conclude, the results proved that vitamin D might offer a potential benefit against UF growth. However, the lack of large population-based clinical trials impedes the validation of the preclinical findings on cells and animals $[13,65]$.

\section{Vitamin D and Uterine Fibroids-Perinatal Implications}

Numerous UF patients with future fertility plans are seeking help from obstetricians/gynecologists. In this review, we focus on UFs and vitamin D, and not pregnancy. We included references for readers interested in the relationship between vitamin D, reproduction, and pregnancy [16, 76-78].

UFs and vitamin D deficiency in pregnant women are separate problems that may cause serious consequences. The first problem of pregnant women who have UFs is connected with a higher risk of spontaneous miscarriages, fetal malpresentation, preterm birth, rupture of membranes, placental abnormalities, emergency cesarean delivery, and postpartum hemorrhage [79]. The second problem is vitamin D deficiency and its complications. Notably, pregnancy is a state of increased calcium demand and fetal vitamin D status is almost completely dependent on the maternal level of vitamin $\mathrm{D}$. The supplementation of vitamin D during pregnancy is necessary, as food sources were found to be inadequate [80].

Therefore, the American Committee of Obstetricians and Gynecologists advised measuring maternal serum 25(OH)D levels and carefully interpreting them in the context of the clinical circumstances in pregnant women at an increased risk of vitamin D deficiency [81]. Similarly, this guideline may be extrapolated to pregnant women with UFs. A combination of UFs and vitamin D deficiency in pregnant women might result in multiple consequences. For example, some complications caused by UFs might be triggered by coexistent vitamin D deficiency and vice versa. In our opinion, fair evidence is available to support the need to monitor vitamin D levels in pregnant women who are at a higher risk of adverse perinatal outcomes $[22,23]$. Considering that UFs are also a potential cause of various perinatal complications, vitamin D screening in pregnant women with UFs might be justified.

\section{Vitamin D and Uterine Fibroids-Available Clinical Data}

Recently, numerous studies have identified low serum concentrations of vitamin $\mathrm{D}$ as important players in the etiology of UFs $[13,45]$. According to available data, cultural and environmental differences might play a major role in UF development [82] and many of them are connected with vitamin D deficiency [49, 82, 83]. For example, Oskovi Kaplan et al. (2018) found that traditional clothing style, low education level, or being a housewife are high-risk factors for UFs [84]. Similar findings were presented by Haq et al. (2018) in which several lifestyle factors such as diet, lack of exercise, cultural habits, and avoiding sun exposure were associated with vitamin D deficiency in women from the Emirates [85].

Although there are some differences regarding vitamin D supplementation geographically, common habits do exist worldwide as well. For example, growing awareness of vita$\min \mathrm{D}$ in the general population and over-the-counter vitamin $\mathrm{D}$, sometimes at very high doses, constitute the risk of uncontrolled use and exogenous hypervitaminosis $\mathrm{D}$, resulting in the high concentrations of serum $25(\mathrm{OH}) \mathrm{D}$ or free 1,25 dihydroxyvitamin $\mathrm{D}[1,25(\mathrm{OH}) 2 \mathrm{D}]$, leading to hypercalciuria and, finally, hypercalcemia considering its fat solubility [86]. It is also important to note that different dosing regimens may have various effects on clinical outcomes. A daily dose leads to stable availability of various vitamin D metabolites, so it could be an important explanation for numerous negative vitamin D intervention trials [87].

Several studies connected low levels of serum vitamin D and UF occurrence. Most of those studies focused on AA women, who have an increased risk of UF development [88-90]. Those populations have a 10 times higher risk of vitamin D deficiency and a 3- to 4-fold higher incidence of UFs compared to Caucasians [91]. Moreover, AA developed UFs earlier and patients presented more severe clinical symptoms $[49,89]$. Most of the research highlights the fact that vitamin D deficiency occurs more often among AA women due to higher melanin concentrations which results in decreased serum vitamin D production, as well as lower dairy consumption due to lactose intolerance [51].

Several epidemiological studies emphasized the important role of vitamin D deficiency in the development of UFs [5, 49-51]. We present the available, up-to-date data relating to vitamin D deficiency to women with UFs in Table 1. 
Table $1 \quad 25$-hydroxyvitamin D serum levels and uterine fibroids among different populations

\begin{tabular}{|c|c|c|c|c|c|}
\hline Country & Author & Year & Number of patients & Results & Type of study \\
\hline USA & Sabry et al. [51] & 2013 & $\begin{array}{l}154 \\
104 \text { cases } \\
50 \text { controls }\end{array}$ & $\begin{array}{l}\text { - Low } 25(\mathrm{OH}) \mathrm{D} \text { levels significantly } \\
\text { associated with UF occurrence } \\
\text { and UF volume. } \\
\text { - Subjects with greater UF volumes } \\
\text { had lower vitamin } \mathrm{D}_{3} \text { serum } \\
\text { concentration. } \\
\text { - Study revealed a significant inverse } \\
\text { correlation between serum } \\
\text { 25(OH)D levels and UF volume } \\
\text { in black patients. }\end{array}$ & Cross-sectional study \\
\hline Italy & Paffoni et al. [50] & 2013 & $\begin{array}{l}384 \\
128 \text { cases } \\
256 \text { controls }\end{array}$ & $\begin{array}{l}\text { - The mean serum level of } 25(\mathrm{OH}) \mathrm{D} \\
\text { was significantly lower in women } \\
\text { with UFs compared to controls. }\end{array}$ & Case-control study \\
\hline USA & Baird et al. [49] & 2013 & $\begin{array}{l}1036 \text { cases } \\
620 \text { black } \\
416 \text { white }\end{array}$ & $\begin{array}{l}\text { - } 10 \% \text { blacks and } 50 \% \text { whites in the } \\
\text { examined group had a sufficient } \\
\text { serum concentration of } 25(\mathrm{OH}) \mathrm{D} \text {. } \\
\text { - Subjects with adequate vitamin D } \\
\text { levels had a lower odds of UFs } \\
\text { compared to the group with } \\
25(\mathrm{OH}) \mathrm{D} \text { deficiency. } \\
\text { - Reported association was similar } \\
\text { for both ethnic groups. Sun } \\
\text { exposure was also correlated with } \\
\text { lower odds of UFs. }\end{array}$ & $\begin{array}{l}\text { National Institute of Environmental } \\
\text { Health Sciences Uterine Fibroid } \\
\text { Study_random selection from } \\
\text { available database }\end{array}$ \\
\hline USA & Mitro et al. [92] & 2015 & 3590 & $\begin{array}{l}\text { - Insufficient } 25(\mathrm{OH}) \mathrm{D} \text { serum } \\
\text { concentration was associated with } \\
\text { UF occurrence in white, but not } \\
\text { black subjects. }\end{array}$ & Cross-sectional study \\
\hline Republic of Congo & Ingala et al. [93] & 2016 & $\begin{array}{l}432 \\
216 \text { cases } \\
216 \text { controls }\end{array}$ & $\begin{array}{l}\text { - } 25(\mathrm{OH}) \mathrm{D} \text { deficiency, especially } \\
\text { using local criteria was observed } \\
\text { in patients with UFs. }\end{array}$ & Case-control study \\
\hline Italy & Ciavattini et al. [52] & 2016 & $\begin{array}{l}108 \\
53 \text { cases } \\
55 \text { controls }\end{array}$ & $\begin{array}{l}\text {-25(OH)D supplementation } \\
\text { re-established normal vitamin D } \\
\text { serum concentration in subjects } \\
\text { with small UFs. } \\
\text { - In these cases vitamin D } \\
\text { supplementation is believed to } \\
\text { reduce the progression of the } \\
\text { disease. }\end{array}$ & Interventional study \\
\hline Indonesia & Masoem et al. [94] & 2017 & $\begin{array}{l}42 \\
21 \text { cases } \\
21 \text { controls }\end{array}$ & $\begin{array}{l}\text { - The mean level of } 25(\mathrm{OH}) \mathrm{D} \text { in the } \\
\text { UF-positive group was signifi- } \\
\text { cantly lower compared to } \\
\text { non-UFs. } \\
\text { - No correlation between the serum } \\
\text { concentration of vitamin D and } \\
\text { the weight of UF mass was } \\
\text { reported. }\end{array}$ & Cross-sectional study \\
\hline Poland & Ciebiera et al. [5] & 2016 & $\begin{array}{l}188 \\
105 \text { cases } \\
83 \text { controls }\end{array}$ & $\begin{array}{l}\text { - Mean } 25(\mathrm{OH}) \mathrm{D} \text { serum levels in } \\
\text { subjects with UFs were } \\
\text { significantly lower. } \\
\text { - Higher TGF- } \beta 3 \text { serum } \\
\text { concentration, BMI, and family } \\
\text { history in the UF group were also } \\
\text { found as the risk factors of UFs. }\end{array}$ & Retrospective cohort study \\
\hline Turkey & Oskovi Kaplan et al. [84] & 2018 & $\begin{array}{l}124 \\
68 \text { cases } \\
56 \text { controls }\end{array}$ & $\begin{array}{l}\text { - No association between vitamin D } \\
\text { serum concentration levels and } \\
\text { size, volume, location, and } \\
\text { number of UFs was found. }\end{array}$ & Cross-sectional study \\
\hline India & Singh et al. [95] & 2019 & $\begin{array}{l}144 \\
72 \text { cases } \\
72 \text { controls }\end{array}$ & $\begin{array}{l}\text { - The mean serum level of } 25(\mathrm{OH}) \mathrm{D} \\
\text { was significantly lower in subjects } \\
\text { with UFs. }\end{array}$ & Cross-sectional study \\
\hline
\end{tabular}


Table 1 (continued)

\begin{tabular}{|c|c|c|c|c|c|}
\hline Country & Author & Year & Number of patients & Results & Type of study \\
\hline & & & & $\begin{array}{l}\text { - In } 62.5 \% \text { of cases, the } \\
\text { concentration of vitamin D3 was } \\
\text { below } 10 \mathrm{ng} / \mathrm{mL} \text {. } \\
\text { - Occurrence of UFs was correlated } \\
\text { with decreased serum } 25(\mathrm{OH}) \mathrm{D} \text {. } \\
\text { - UFs were associated with }\end{array}$ & \\
\hline India & Kumari et al. [96] & 2019 & $\begin{array}{l}80 \\
40 \text { cases } \\
40 \text { controls }\end{array}$ & $\begin{array}{l}\text { - UFs were associated with } \\
\text { multipara subjects without a } \\
\text { medical history of contraceptive } \\
\text { pill administration. } \\
\text { - Significant decrease in vitamin D } \\
\text { and calcium serum levels in cases } \\
\text { with significant negative } \\
\text { association between vitamin D, } \\
\text { and the size of UFs was observed. }\end{array}$ & Case-control study \\
\hline Iran & Beygi et al. [97] & 2019 & $\begin{array}{l}106 \\
53 \text { cases } \\
53 \text { controls }\end{array}$ & $\begin{array}{l}\text { - An association between high } \\
\text { vitamin D serum concentration } \\
\text { levels and reduced lesion volume } \\
\text { was found. } \\
\text { - Subjects with vitamin D } \\
\text { administration had a reduced } \\
\text { tumor volume. The number of } \\
\text { lesions was not correlated with } \\
25(\mathrm{OH}) \mathrm{D} \text {. }\end{array}$ & Randomized controlled trial \\
\hline Iran & Hajhashemi et al. [98] & 2019 & $\begin{array}{l}69 \\
35 \text { cases } \\
34 \text { controls }\end{array}$ & $\begin{array}{l}\text { - UF size in a group with the } \\
\text { administration of } 25(\mathrm{OH}) \mathrm{D} \text { was } \\
\text { significantly reduced compared to } \\
\text { placebo. }\end{array}$ & Randomized controlled trial \\
\hline India & Srivastava et al. [99] & 2019 & $\begin{array}{l}90 \\
45 \text { cases } \\
45 \text { controls }\end{array}$ & $\begin{array}{l}\text { - Significantly lower mean } \\
\text { concentration of } 25(\mathrm{OH}) \mathrm{D} \text { in UF } \\
\text { cases compared to controls. } \\
\text { - UFs' size increased with low } \\
25(\mathrm{OH}) \mathrm{D} \text { concentration. Vitamin } \\
\text { D deficiency is associated with } \\
\text { UF occurrence. }\end{array}$ & Cross-sectional study \\
\hline Iran & Arjeh et al. [100] & 2020 & $\begin{array}{l}60 \\
30 \text { cases } \\
30 \text { controls }\end{array}$ & $\begin{array}{l}\text { - No statistically significant decrease } \\
\text { in the volume of fibroids was } \\
\text { observed in vitamin D treatment } \\
\text { group. However, a significant } \\
\text { increase was observed in the size } \\
\text { of fibroids in the control group. }\end{array}$ & Randomized controlled trial \\
\hline China & Li et al. [101] & 2020 & 546 & $\begin{array}{l}\text { - Women with UFs had lower serum } \\
25(\mathrm{OH}) \mathrm{D} \text { levels versus those } \\
\text { without fibroids. }\end{array}$ & Case-control study \\
\hline
\end{tabular}

The data in Table 1 highlight the clear connections between vitamin D deficiency and UF occurrence. However, more research is required in this field. Only Mitro et al. (2015) found no association between low vitamin D levels and the appearance of UFs within the entire population. Interestingly, in this study, the decreased serum concentration of vitamin D was a risk factor of UFs in white women, but no such correlation was observed in black women [92].

Since vitamin D was proved to stop or slow down the growth of UFs both in vitro and in vivo, as well as in limited clinical trials $[52,66]$, there would be a point in measuring its level in women who were diagnosed with UFs, especially in those who presented with clinical symptoms. If vitamin D deficiency is diagnosed, proper supplementation should be implemented to slow down UF growth. In our opinion, 25(OH)D serum level measurement in selected women could be the simplest, inexpensive, and effective procedure in UF prevention. The same approach may be extended to women who are at a high risk of UFs $[13,45,102]$.

\section{5-Hydroxyvitamin D Measurements in Women at a High Risk of Uterine Fibroids-Clinical Guidance}

Considering the above, herein we propose recommendations for 25(OH)D measurements in patients who are at risk of developing UFs and in UF patients as well. Our clinical guidance on 25( $\mathrm{OH}) \mathrm{D}$ serum level measurements is presented in Table 2. 
Table 2 Clinical situations or risk factors that might qualify for 25-hydroxyvitamin D testing

Clinical situation or risk factor

Uterine fibroids:

- Clinically symptomatic

- Increase in volume

- Multiple and large burden

- Pregnancy

Women of black race with uterine fibroids

Asymptomatic or smaller uterine fibroids

Premenopausal status

$>40$ years of age

Positive family history for uterine fibroids

$>10$ years since last birth

Nulliparous

Chronic hypertension

Food additives and soybean milk frequent use

Low sun exposure

Obesity

Low physical activity

Alcohol use

Red meat-rich diet

Early menarche

Other factors

Previous vitamin D supplementation/treatment without proper control 25-hydroxyvitamin D serum level test

Recommended if any factors present

Depends on the menopausal status and reproductive plans

Clinicians should individualize their management, measurements in the presence of additional risk factors (see below)

Depends on additional factors and further reproductive plans

Clinicians should individualize their management, measurements in the presence of additional risk factors (see below)

Additional risk factors (stronger)

Additional risk factors (weaker)

Also to exclude the risk of potential toxicity
It is only a preliminary proposal and an introduction to the topic, as even with available data, still more research is required to provide well-established evidence-based clinical guidelines $[13,45]$.

\section{Vitamin D Supplementation in Selected Groups}

Generally, the amount of vitamin D sufficient to restore the normal level of $25(\mathrm{OH}) \mathrm{D}$ depends on various criteria including age, weight, skin color, sun exposure, diet, and medical conditions. However, a huge gap still exists between recommended vitamin D dose intake and the poor supply in the general population.

The available forms of supplementation and medications include vitamin $D_{2}$ and vitamin $D_{3}$. Vitamin $D_{3}$ is believed to elevate its serum levels more effectively [19]. According to Cochrane review by Bjelakovic et al. published in 2014, vita$\min \mathrm{D}_{3}$ seemed to decrease mortality in elderly people, whereas vitamin $\mathrm{D}_{2}$ and others did not have statistically significant beneficial effects on the mortality rate [103]. The dose of vitamin $\mathrm{D}$ depends upon the nature and severity of the deficiency. A recommended dose of daily vitamin D intake needed to achieve an optimal skeletal effect is about 400 800 international units (IU) [17]. According to Płudowski et al. (2018), guidelines focused on the pleiotropic effects of vitamin $\mathrm{D}$ recommended a target $25(\mathrm{OH}) \mathrm{D}$ serum level of more than $30 \mathrm{ng} / \mathrm{mL}$, depending on age, weight, additional diseases, and ethnicity. Thus, the recommended daily vitamin D doses range from 400 to $2000 \mathrm{IU}$. While the natural sources of vitamin D may slightly raise $25(\mathrm{OH}) \mathrm{D}$ concentrations, they are still mostly ineffective to maintain the year-round 25(OH)D concentrations [28].

As stated by Rusińska et al. in 2019, there is a great necessity to implement regular vitamin D supplementation with recommended doses and to develop an effective strategy to alleviate vitamin D deficiency [18]. In patients who suffer from severe deficiency, treatment doses are used. The exact guidelines are not the topic of this paper and the reader is advised to check the current guidelines that might differ according to the country, expert groups or medical societies. However, many clinicians use the standard doses of about 7000 IU daily or 50,000 IU per week [18], as such a treatment is easy to implement with available products. It is also of importance to add $1000 \mathrm{mg}$ of calcium (diet and 
supplementation) each day during deficiency treatment [104] or even $1200 \mathrm{mg}$ [105] or $1300 \mathrm{mg}$ [18] in postmenopausal women as it reduces bone turnover [105].

As for monitoring, vitamin $\mathrm{D}$ treatment in deficient or insufficient women, experts advise measuring $25(\mathrm{OH}) \mathrm{D}$ serum level after 3 months (depending on clinical situation). Treatment should be continued until $25(\mathrm{OH}) \mathrm{D}$ concentration of about $30-50 \mathrm{ng} / \mathrm{mL}$ is reached [18], or $40-60 \mathrm{ng} / \mathrm{mL}$ as suggested in guidelines by Płudowski et al. [28]. Once achieved, maintenance dose is recommended $[18,33]$.

Still, the main problem in our field is the lack of consensus about the threshold and optimal levels which is important to perform good quality clinical trials. The consensus in this area may bring great benefits to women with UFs, and probably levels above $30 \mathrm{ng} / \mathrm{mL}$ should be of clinical importance in this problem. In our opinion, patients who are at a high risk of UFs, e.g., obese, elderly, nulliparous, of black race, and those with a positive family history or early menarche, should be screened and offered proper treatment with vitamin $\mathrm{D}$, if necessary $[5,13,106]$. For the suggested guidance in different indications, please refer to Table 2.

As mentioned by Mohamed et al. in 2016, the routine screening of pregnant patients for vitamin D deficiency was conducted by large group of clinicians and studies showed the benefits of vitamin D supplementation in those women [107]. Similarly, we believe it will soon become the daily practice of clinicians who treat women with UFs.

Notably, the response to vitamin D medications might differ among populations and even in the same person [108], as up to $25 \%$ of humanity present with slow response after standard supplementation doses. We still do not measure the exact vitamin $\mathrm{D}$ response index, but it might be of interest for future studies. For example, similar doses of vitamin D in a high responder group may result in high elevations of $25(\mathrm{OH}) \mathrm{D}$ serum levels and the subsequent retention of tumor growth, whereas low responders will only gain a slight elevation of 25(OH)D serum level or even no effect at all [108].

\section{Conclusions}

According to recent data and ongoing research, vitamin D seems to be a promising and cost-effective anti-UF agent. More large well-designed randomized clinical studies are needed to explore the efficiency of vitamin D in women with UFs of all ethnicities, especially women of color that have a higher risk of vitamin D deficiency. Thus, vitamin D could become an option in UF therapy with the additional advantage of its beneficial pleiotropic effect. We hope that ongoing studies will provide a reliable answer. So far, limited trials have been conducted with few participants, less diverse populations, or short-term therapy testing.
Achieving sufficient serum levels of vitamin D might be of interest in patients with UFs. Screening, supplementation, treatment guidelines, and public health strategies for vitamin D deficiency in women with UFs as well as women at a high risk of UF development might be of potential importance as well. In this manuscript, we proposed a preliminary clinical instruction of 25(OH)D measurements for gynecologists and other clinicians who are involved in the treatment of patients with UFs.

Author Contributions Conceptualization: Michał Ciebiera, Mohamed Ali, Lillian Prince, Stanisław Zgliczyński, Grzegorz Jakiel, and Ayman Al-Hendy; methodology: Michał Ciebiera, Mohamed Ali; validation, Michał Ciebiera, Mohamed Ali, Lillian Prince, and Stanisław Zgliczyński; formal analysis: Michał Ciebiera, Mohamed Ali; data curation, Michał Ciebiera, Mohamed Ali, and Stanisław Zgliczyński; writing - original draft preparation: Michał Ciebiera, Mohamed Ali, Lillian Prince, and Stanisław Zgliczyński; writing - review and editing: Ayman Al-Hendy; visualization, Michał Ciebiera, Grzegorz Jakiel, and Ayman Al-Hendy; supervision: Michał Ciebiera, Grzegorz Jakiel, and Ayman Al-Hendy; funding acquisition: Ayman Al-Hendy. All authors have read and agreed to the published version of the manuscript.

Funding This study was partially supported by the National Institute of Health grants: R01 HD094378-04, R01 ES 028615-02, R01 HD10036701, U54 MD007602, and R01 HD094380-02.

Michal Ciebiera scholarship in the USA was founded by The Kosciuszko Foundation, The American Center of Polish Culture.

\section{Compliance with Ethical Standards}

Conflict of Interest Ayman Al-Hendy is a consultant for Abbvie, Allergan, Bayer, Myovant Sciences, and Repros. No conflicts were declared for the remaining authors.

Open Access This article is licensed under a Creative Commons Attribution 4.0 International License, which permits use, sharing, adaptation, distribution and reproduction in any medium or format, as long as you give appropriate credit to the original author(s) and the source, provide a link to the Creative Commons licence, and indicate if changes were made. The images or other third party material in this article are included in the article's Creative Commons licence, unless indicated otherwise in a credit line to the material. If material is not included in the article's Creative Commons licence and your intended use is not permitted by statutory regulation or exceeds the permitted use, you will need to obtain permission directly from the copyright holder. To view a copy of this licence, visit http://creativecommons.org/licenses/by/4.0/.

\section{References}

1. Stewart EA, Laughlin-Tommaso SK, Catherino WH, Lalitkumar S, Gupta D, Vollenhoven B. Uterine fibroids. Nat Rev Dis Primers. 2016;2:16043.

2. Ulin M, Ali M, Chaudhry ZT, Al-Hendy A, Yang Q. Uterine fibroids in menopause and perimenopause. Menopause. 2020;27(2):238-42.

3. Wise LA, Laughlin-Tommaso SK. Epidemiology of uterine fibroids: from menarche to menopause. Clin Obstet Gynecol. 2016;59(1):2-24. 
4. Stewart EA, Cookson CL, Gandolfo RA, Schulze-Rath R. Epidemiology of uterine fibroids: a systematic review. BJOG. 2017;124(10):1501-12.

5. Ciebiera M, Wlodarczyk M, Slabuszewska-Jozwiak A, Nowicka G, Jakiel G. Influence of vitamin D and transforming growth factor beta3 serum concentrations, obesity, and family history on the risk for uterine fibroids. Fertil Steril. 2016;106(7):1787-92.

6. Parker WH. Etiology, symptomatology, and diagnosis of uterine myomas. Fertil Steril. 2007;87(4):725-36.

7. Al-Hendy A, Myers ER, Stewart E. Uterine fibroids: burden and unmet medical need. Semin Reprod Med. 2017;35(6):473-80.

8. Donnez J, Dolmans MM. Uterine fibroid management: from the present to the future. Hum Reprod Update. 2016;22(6):665-86.

9. Soliman AM, Yang H, Du EX, Kelkar SS, Winkel C. The direct and indirect costs of uterine fibroid tumors: a systematic review of the literature between 2000 and 2013. Am J Obstet Gynecol. 2015;213(2):141-60.

10. Merrill RM. Hysterectomy surveillance in the United States, 1997 through 2005. Med Sci Monit. 2008;14(1):CR24-31.

11. Becker ER. National trends and determinants of hospitalization costs and lengths-of-stay for uterine fibroids procedures. J Health Care Finance. 2007;33(3):1-16.

12. Blauer M, Rovio PH, Ylikomi T, Heinonen PK. Vitamin D inhibits myometrial and leiomyoma cell proliferation in vitro. Fertil Steril. 2009;91(5):1919-25.

13. Ciebiera M, Wlodarczyk M, Ciebiera M, Zareba K, Lukaszuk K, Jakiel G. Vitamin D and uterine fibroids-review of the literature and novel concepts. Int J Mol Sci. 2018;19(7):2051

14. Holick MF. Vitamin D deficiency. N Engl J Med. 2007;357(3): 266-81.

15. Tripkovic L, Lambert H, Hart K, Smith CP, Bucca G, Penson S, et al. Comparison of vitamin D2 and vitamin D3 supplementation in raising serum 25-hydroxyvitamin D status: a systematic review and meta-analysis. Am J Clin Nutr. 2012;95(6):1357-64.

16. Pilz S, Zittermann A, Obeid R, Hahn A, Pludowski P, Trummer C, et al. The role of vitamin $\mathrm{D}$ in fertility and during pregnancy and lactation: a review of clinical data. Int J Environ Res Public Health. 2018;15(10):2241.

17. Pilz S, Marz W, Cashman KD, Kiely ME, Whiting SJ, Holick MF, et al. Rationale and plan for vitamin D food fortification: a review and guidance paper. Front Endocrinol (Lausanne). 2018;9:373.

18. Rusinska A, Pludowski P, Walczak M, Borszewska-Kornacka MK, Bossowski A, Chlebna-Sokol D, et al. Vitamin D supplementation guidelines for general population and groups at risk of vitamin D deficiency in Poland-Recommendations of the Polish Society of Pediatric Endocrinology and Diabetes and the Expert Panel With Participation of National Specialist Consultants and Representatives of Scientific Societies-2018 Update. Front Endocrinol (Lausanne). 2018;9:246.

19. Nair R, Maseeh A. Vitamin D: The "sunshine" vitamin. J Pharmacol Pharmacother. 2012;3(2):118-26.

20. Ross AC, Manson JE, Abrams SA, Aloia JF, Brannon PM, Clinton SK, et al. The 2011 report on dietary reference intakes for calcium and vitamin D from the Institute of Medicine: what clinicians need to know. J Clin Endocrinol Metab. 2011;96(1):53-8.

21. Pludowski P, Holick MF, Pilz S, Wagner CL, Hollis BW, Grant WB, et al. Vitamin D effects on musculoskeletal health, immunity, autoimmunity, cardiovascular disease, cancer, fertility, pregnancy, dementia and mortality-a review of recent evidence. Autoimmun Rev. 2013;12(10):976-89.

22. Pludowski P, Grant WB, Konstantynowicz J, Holick MF. Editorial: Classic and pleiotropic actions of vitamin D. Front Endocrinol (Lausanne). 2019;10:341.

23. Ciebiera M, Wlodarczyk M, Wojtyla C, Łukaszuk K, Zgliczyńska $\mathrm{M}$, Zareba K, et al. The role of vitamin D in perinatology - what do we know at the beginning of 2018 ? An up-to-date review. Arch Med Sci. 2019.

24. Gaksch M, Jorde R, Grimnes G, Joakimsen R, Schirmer H, Wilsgaard T, et al. Vitamin D and mortality: individual participant data meta-analysis of standardized 25-hydroxyvitamin D in 26916 individuals from a European consortium. PLoS One. 2017;12(2): e0170791.

25. Zhang Y, Fang F, Tang J, Jia L, Feng Y, Xu P, et al. Association between vitamin $\mathrm{D}$ supplementation and mortality: systematic review and meta-analysis. BMJ. 2019;366:14673.

26. Wacker M, Holick MF. Sunlight and vitamin D: a global perspective for health. Dermatoendocrinol. 2013;5(1):51-108.

27. Spiro A, Buttriss JL. Vitamin D: An overview of vitamin D status and intake in Europe. Nutr Bull. 2014;39(4):322-50.

28. Pludowski P, Holick MF, Grant WB, Konstantynowicz J, Mascarenhas MR, Haq A, et al. Vitamin D supplementation guidelines. J Steroid Biochem Mol Biol. 2018;175:125-35.

29. Rosen CJ. Clinical practice. Vitamin D insufficiency. N Engl J Med. 2011;364(3):248-54.

30. Rosen CJ, Abrams SA, Aloia JF, Brannon PM, Clinton SK, Durazo-Arvizu RA, et al. IOM committee members respond to Endocrine Society vitamin D guideline. J Clin Endocrinol Metab. 2012;97(4):1146-52.

31. Holick MF, Binkley NC, Bischoff-Ferrari HA, Gordon CM, Hanley DA, Heaney RP, et al. Evaluation, treatment, and prevention of vitamin D deficiency: an Endocrine Society clinical practice guideline. J Clin Endocrinol Metab. 2011;96(7):1911-30.

32. Holick MF. Vitamin D status: measurement, interpretation, and clinical application. Ann Epidemiol. 2009;19(2):73-8.

33. Pilz S, Zittermann A, Trummer C, Theiler-Schwetz V, Lerchbaum E, Keppel MH, et al. Vitamin D testing and treatment: a narrative review of current evidence. Endocr Connect. 2019;8(2):R27-43.

34. Holick MF, Binkley NC, Bischoff-Ferrari HA, Gordon CM, Hanley DA, Heaney RP, et al. Guidelines for preventing and treating vitamin D deficiency and insufficiency revisited. J Clin Endocrinol Metab. 2012;97(4):1153-8.

35. Bulun SE. Uterine fibroids. N Engl J Med. 2013;369(14):1344-55.

36. Soave I, Marci R. Uterine leiomyomata: the snowball effect. Curr Med Res Opin. 2017;33(11):1909-11.

37. Islam MS, Ciavattini A, Petraglia F, Castellucci M, Ciarmela P. Extracellular matrix in uterine leiomyoma pathogenesis: a potential target for future therapeutics. Hum Reprod Update. 2018;24(1):59-85

38. Ishikawa H, Ishi K, Serna VA, Kakazu R, Bulun SE, Kurita T. Progesterone is essential for maintenance and growth of uterine leiomyoma. Endocrinology. 2010;151(6):2433-42.

39. Chill HH, Safrai M, Reuveni Salzman A, Shushan A. The rising Phoenix-progesterone as the main target of the medical therapy for leiomyoma. Biomed Res Int. 2017;2017:4705164.

40. Borahay MA, Al-Hendy A, Kilic GS, Boehning D. Signaling pathways in leiomyoma: understanding pathobiology and implications for therapy. Mol Med. 2015;21:242-56.

41. Ciarmela P, Islam MS, Reis FM, Gray PC, Bloise E, Petraglia F, et al. Growth factors and myometrium: biological effects in uterine fibroid and possible clinical implications. Hum Reprod Update. 2011;17(6):772-90.

42. Protic O, Toti P, Islam MS, Occhini R, Giannubilo SR, Catherino $\mathrm{WH}$, et al. Possible involvement of inflammatory/reparative processes in the development of uterine fibroids. Cell Tissue Res. 2016;364(2):415-27.

43. Ciebiera M, Wlodarczyk M, Wrzosek M, Meczekalski B, Nowicka G, Lukaszuk K, et al. Role of transforming growth factor beta in uterine fibroid biology. Int J Mol Sci. 2017;18(11):2435.

44. Ciebiera M, Wlodarczyk M, Zgliczynska M, Lukaszuk K, Meczekalski B, Kobierzycki C, et al. The role of tumor necrosis 
factor alpha in the biology of uterine fibroids and the related symptoms. Int J Mol Sci. 2018;19(12):3869.

45. Brakta S, Diamond JS, Al-Hendy A, Diamond MP, Halder SK. Role of vitamin D in uterine fibroid biology. Fertil Steril. 2015;104(3):698-706.

46. Al-Hendy A, Diamond MP, Boyer TG, Halder SK. Vitamin D3 inhibits Wnt/beta-catenin and mTOR signaling pathways in human uterine fibroid cells. J Clin Endocrinol Metab. 2016;101(4): $1542-51$.

47. Elhusseini H, Elkafas H, Abdelaziz M, Halder S, Atabiekov I, Eziba N, et al. Diet-induced vitamin D deficiency triggers inflammation and DNA damage profile in murine myometrium. Int $\mathrm{J}$ Women's Health. 2018;10:503-14.

48. Kim CH. A functional relay from progesterone to vitamin $\mathrm{D}$ in the immune system. DNA Cell Biol. 2015;34(6):379-82.

49. Baird DD, Hill MC, Schectman JM, Hollis BW. Vitamin d and the risk of uterine fibroids. Epidemiology. 2013;24(3):447-53.

50. Paffoni A, Somigliana E, Vigano P, Benaglia L, Cardellicchio L, Pagliardini L, et al. Vitamin D status in women with uterine leiomyomas. J Clin Endocrinol Metab. 2013;98(8):E1374-8.

51. Sabry M, Halder SK, Allah AS, Roshdy E, Rajaratnam V, AlHendy A. Serum vitamin D3 level inversely correlates with uterine fibroid volume in different ethnic groups: a cross-sectional observational study. Int J Women's Health. 2013;5:93-100.

52. Ciavattini A, Delli Carpini G, Serri M, Vignini A, Sabbatinelli J, Tozzi A, et al. Hypovitaminosis D and "small burden" uterine fibroids: opportunity for a vitamin D supplementation. Medicine (Baltimore). 2016;95(52):e5698.

53. Ali M, Shahin SM, Sabri NA, Al-Hendy A, Yang Q. 1,25 Dihydroxyvitamin D3 enhances the antifibroid effects of ulipristal acetate in human uterine fibroids. Reprod Sci. 2019;26(6):81228.

54. Ciebiera M, Meczekalski B, Lukaszuk K, Jakiel G. Potential synergism between ulipristal acetate and vitamin D3 in uterine fibroid pharmacotherapy - 2 case studies. Gynecol Endocrinol. 2019;35(6):473-7.

55. Palacios $\mathrm{C}$, Gonzalez L. Is vitamin D deficiency a major global public health problem? J Steroid Biochem Mol Biol. 2014;144 Pt A:138-45.

56. Pludowski P, Ducki C, Konstantynowicz J, Jaworski M. Vitamin D status in Poland. Pol Arch Med Wewn. 2016;126(7-8):530-9.

57. Kennel KA, Drake MT, Hurley DL. Vitamin D deficiency in adults: when to test and how to treat. Mayo Clin Proc. 2010;85(8):752-7 quiz 7-8.

58. Walsh JS, Bowles S, Evans AL. Vitamin D in obesity. Curr Opin Endocrinol Diabetes Obes. 2017;24(6):389-94.

59. LeFevre ML, U.S. Preventive Services Task Force. Screening for vitamin D deficiency in adults: U.S. Preventive Services Task Force recommendation statement. Ann Intern Med. 2015;162(2): 133-40.

60. Souberbielle JC, Benhamou CL, Cortet B, Rousiere M, Roux C, Abitbol V, et al. French law: what about a reasoned reimbursement of serum vitamin D assays? Geriatr Psychol Neuropsychiatr Vieil. 2016;14(4):377-82.

61. Raman M, Milestone AN, Walters JR, Hart AL, Ghosh S. Vitamin $\mathrm{D}$ and gastrointestinal diseases: inflammatory bowel disease and colorectal cancer. Ther Adv Gastroenterol. 2011;4(1):49-62.

62. Sowah D, Fan X, Dennett L, Hagtvedt R, Straube S. Vitamin D levels and deficiency with different occupations: a systematic review. BMC Public Health. 2017;17(1):519.

63. Wu JL, Segars JH. Is vitamin D the answer for prevention of uterine fibroids? Fertil Steril. 2015;104(3):559-60.

64. Ali M, Al-Hendy A, Yang Q. Vitamin D, a promising natural compound with anti-uterine fibroid characteristics. Fertil Steril. 2019;111(2):268-9.
65. Ali M, Prince L, Al-Hendy A. Vitamin D and uterine fibroids: preclinical evidence is in; time for an overdue clinical study! Fertil Steril. 2020;113(1):89-90.

66. Corachan A, Ferrero H, Aguilar A, Garcia N, Monleon J, Faus A, et al. Inhibition of tumor cell proliferation in human uterine leiomyomas by vitamin D via Wnt/beta-catenin pathway. Fertil Steril. 2019;111(2):397-407.

67. Halder SK, Goodwin JS, Al-Hendy A. 1,25-Dihydroxyvitamin D3 reduces TGF-beta3-induced fibrosis-related gene expression in human uterine leiomyoma cells. J Clin Endocrinol Metab. 2011;96(4):E754-62.

68. Sharan C, Halder SK, Thota C, Jaleel T, Nair S, Al-Hendy A. Vitamin D inhibits proliferation of human uterine leiomyoma cells via catechol-O-methyltransferase. Fertil Steril. 2011;95(1):24753.

69. Halder SK, Sharan C, Al-Hendy A. 1,25-dihydroxyvitamin D3 treatment shrinks uterine leiomyoma tumors in the Eker rat model. Biol Reprod. 2012;86(4):116.

70. Othman ER, Ahmed E, Sayed AA, Hussein M, Abdelaal II, Fetih AN, et al. Human uterine leiomyoma contains low levels of 1, 25 dihdroxyvitamin D3, and shows dysregulated expression of vitamin D metabolizing enzymes. Eur J Obstet Gynecol Reprod Biol. 2018;229:117-22.

71. Ali M, Shahin SM, Sabri NA, Al-Hendy A, Yang Q. Hypovitaminosis D exacerbates the DNA damage load in human uterine fibroids, which is ameliorated by vitamin D3 treatment. Acta Pharmacol Sin. 2019;40(7):957-70.

72. Corachan A, Ferrero H, Escrig J, Monleon J, Faus A, Cervello I, et al. Long-term vitamin D treatment decreases human uterine leiomyoma size in a xenograft animal model. Fertil Steril. 2020;113(1):205-16 e4.

73. Courtoy GE, Donnez J, Marbaix E, Dolmans MM. In vivo mechanisms of uterine myoma volume reduction with ulipristal acetate treatment. Fertil Steril. 2015;104(2):426-34 e1.

74. Donnez J, Arriagada P, Marciniak M, Larrey D. Liver safety parameters of ulipristal acetate for the treatment of uterine fibroids: a comprehensive review of the clinical development program. Expert Opin Drug Saf. 2018;17(12):1225-32.

75. Indraccolo U, Conzadori S, Greco P. Which is the destiny of ulipristal acetate for uterine fibroids? A commentary on the Italian medicines agency (AIFA) pronouncements. Recenti Prog Med. 2019;110(2):98-9.

76. Skowronska P, Pastuszek E, Kuczynski W, Jaszczol M, Kuc P, Jakiel $\mathrm{G}$, et al. The role of vitamin $\mathrm{D}$ in reproductive dysfunction in women - a systematic review. Ann Agric Environ Med. 2016;23(4):671-6.

77. Bialy L, Fenton T, Shulhan-Kilroy J, Johnson DW, McNeil DA, Hartling L. Vitamin D supplementation to improve pregnancy and perinatal outcomes: an overview of 42 systematic reviews. BMJ Open. 2020;10(1):e032626.

78. Royal College of Obstetricians and, Gynaecologists (RCOG). Vitamin D in pregnancy 2014 [Scientific Impact Paper No. 43]. Available from: https://www.rcog.org.uk/globalassets/ documents/guidelines/scientific-impact-papers/vitamin_d_sip43 june14.pdf. Accessed 27 Sept 2020.

79. Zhao R, Wang X, Zou L, Li G, Chen Y, Li C, et al. Adverse obstetric outcomes in pregnant women with uterine fibroids in China: a multicenter survey involving 112,403 deliveries. PLoS One. 2017;12(11):e0187821.

80. Skowrońska-Jóźwiak E, Adamczewski Z, Tyszkiewicz A, Krawczyk-Rusiecka K, Lewandowski K, Lewiński A. Assessment of adequacy of vitamin $\mathrm{D}$ supplementation during pregnancy. Ann Agric Environ Med. 2014;21(1):198-200.

81. American College of Obstetricians and Gynecologists (ACOG) Committee on Obstetric Practice. ACOG Committee Opinion 
No. 495: vitamin D: screening and supplementation during pregnancy. Obstet Gynecol. 2011;118(1):197-8.

82. Catherino WH, Eltoukhi HM, Al-Hendy A. Racial and ethnic differences in the pathogenesis and clinical manifestations of uterine leiomyoma. Semin Reprod Med. 2013;31(5):370-9.

83. Zhao G, Ford ES, Tsai J, Li C, Croft JB. Factors associated with vitamin $\mathrm{D}$ deficiency and inadequacy among women of childbearing age in the United States. ISRN Obstet Gynecol. 2012;2012: 691486

84. Oskovi Kaplan ZA, Tasci Y, Topcu HO, Erkaya S. 25-Hydroxy vitamin D levels in premenopausal Turkish women with uterine leiomyoma. Gynecol Endocrinol. 2018;34(3):261-4.

85. Haq A, Wimalawansa SJ, Pludowski P, Anouti FA. Clinical practice guidelines for vitamin D in the United Arab Emirates. J Steroid Biochem Mol Biol. 2018;175:4-11.

86. Marcinowska-Suchowierska E, Kupisz-Urbanska M, Lukaszkiewicz J, Pludowski P, Jones G. Vitamin D toxicity-a clinical perspective. Front Endocrinol (Lausanne). 2018;9:550.

87. Amrein K, Scherkl M, Hoffmann M, Neuwersch-Sommeregger S, Kostenberger M, Tmava Berisha A, et al. Vitamin D deficiency 2.0: an update on the current status worldwide. Eur J Clin Nutr. 2020.

88. Baird DD, Harmon QE, Upson K, Moore KR, Barker-Cummings $\mathrm{C}$, Baker S, et al. A prospective, ultrasound-based study to evaluate risk factors for uterine fibroid incidence and growth: methods and results of recruitment. J Women's Health (Larchmt). 2015;24(11):907-15.

89. Wise LA. Study of environment lifestyle and fibroids (SELF): advancing the field of fibroid epidemiology. J Women's Health (Larchmt). 2015;24(11):862-4.

90. Baird DD, Patchel SA, Saldana TM, Umbach DM, Cooper T, Wegienka $\mathrm{G}$, et al. Uterine fibroid incidence and growth in an ultrasound-based, prospective study of young AfricanAmericans. Am J Obstet Gynecol. 2020;223(3):P402.E1402.E18

91. Farquhar CM, Steiner CA. Hysterectomy rates in the United States 1990-1997. Obstet Gynecol. 2002;99(2):229-34.

92. Mitro SD, Zota AR. Vitamin D and uterine leiomyoma among a sample of US women: findings from NHANES, 2001-2006. Reprod Toxicol. 2015;57:81-6.

93. Ingalaa $\mathrm{P}$, Mboloko J, Tshiband A, Lepira F, Kayembe P, Lebwaze B, et al. Vitamin D deficiency and risk of uterine leiomyoma among Congolese women. A hospital-based casecontrol study. Am Sci Res J Eng Technol Sci. 2016;22(1):126-37.

94. Masoem AP, Djuwantono T, Ritonga MA, Effendi JS, Permadi W, Madjid TH. Perbandingan Kadar 25-(OH)-Vitamin D3 pada Serum Kelompok Mioma Uteri dan Non-Mioma Uteri. Indones J Obstet Ginecol Sci. 2019;2(1):52-9.

95. Singh V, Barik A, Imam N. Vitamin D3 level in women with uterine fibroid: an observational study in eastern Indian population. J Obstet Gynaecol India. 2019;69(2):161-5.
96. Kumari S, Babu BD, Singh S. Association of vitamin D, calcium and phosphate with uterine fibroid in premenopausal women of Coastal Odisha. Int J Sci Res. 2019;8(2):27-9.

97. Beygi RM, Rakhshandeh M. Role of vitamin D in shrinkage of uterine leiomyoma in 20-50 years old women with vitamin D deficiency. J Ischemia Tissue Repair. 2019;3:e06.

98. Hajhashemi M, Ansari M, Haghollahi F, Eslami B. The effect of vitamin $\mathrm{D}$ supplementation on the size of uterine leiomyoma in women with vitamin D deficiency. Caspian J Intern Med. 2019;10(2):125-31.

99. Srivastava P, Gupta HP, Singhi S, Khanduri S, Rathore B. Evaluation of 25-hydroxy vitamin D3 levels in patients with a fibroid uterus. J Obstet Gynaecol. 2020;40(5):710-4.

100. Arjeh S, Darsareh F, Asl ZA, Azizi KM. Effect of oral consumption of vitamin $\mathrm{D}$ on uterine fibroids: a randomized clinical trial. Complement Ther Clin Pract. 2020;39:101159.

101. Li S, Chen B, Sheng B, Wang J, Zhu X. The associations between serum vitamin $\mathrm{D}$, calcium and uterine fibroids in Chinese women: a case-controlled study. J Int Med Res. 2020;48(5): 300060520923492.

102. Ciebiera M, Lukaszuk K, Meczekalski B, Ciebiera M, Wojtyla C, Slabuszewska-Jozwiak A, et al. Alternative oral agents in prophylaxis and therapy of uterine fibroids-an up-to-date review. Int $\mathrm{J}$ Mol Sci. 2017;18(12):2586

103. Bjelakovic G, Gluud LL, Nikolova D, Whitfield K, Wetterslev J, Simonetti RG, et al. Vitamin D supplementation for prevention of mortality in adults. Cochrane Database Syst Rev. 2014;1: CD007470.

104. Kahwati LC, Weber RP, Pan H, Gourlay M, LeBlanc E, CokerSchwimmer M, et al. Vitamin D, calcium, or combined supplementation for the primary prevention of fractures in communitydwelling adults: evidence report and systematic review for the US preventive services task force. JAMA. 2018;319(15):1600-12.

105. Aloia JF, Dhaliwal R, Shieh A, Mikhail M, Islam S, Yeh JK. Calcium and vitamin d supplementation in postmenopausal women. J Clin Endocrinol Metab. 2013;98(11):E1702-9.

106. Ali M, Chaudhry ZT, Al-Hendy A. Successes and failures of uterine leiomyoma drug discovery. Expert Opin Drug Discovery. 2018;13(2):169-77.

107. Mohamed SA, Al-Hendy A, Schulkin J, Power ML. Opinions and practice of US-based obstetrician-gynecologists regarding vitamin D screening and supplementation of pregnant women. J Pregnancy. 2016;2016:1454707.

108. Carlberg C, Haq A. The concept of the personal vitamin D response index. J Steroid Biochem Mol Biol. 2018;175:12-7.

Publisher's Note Springer Nature remains neutral with regard to jurisdictional claims in published maps and institutional affiliations. 